\title{
A ESCARIFICAÇÃO QUÍMICA E O DESENVOLVIMENTO INICIAL DE PORTA-ENXERTOS CÍTRICOS ${ }^{1}$
}

\author{
PAULO DE TARSO LIMA TEIXEIRA², GILMAR SCHÄFER ${ }^{3}$, \\ PAULO VITOR DUTRA DE SOUZA ${ }^{4}$, ABEL TODESCHINI $^{5}$
}

RESUMO - O objetivo deste trabalho foi avaliar a emergência e o desenvolvimento vegetativo de diferentes porta-enxertos cítricos provenientes de sementes escarificadas quimicamente. O delineamento experimental adotado foi o de blocos ao acaso, em esquema fatorial $2 \times 4$ (escarificação x porta-enxertos), com três blocos, e cada parcela constituída por 20 tubetes. O tratamento químico realizado nas sementes constituiu-se de uma solução composta por $0,5 \mathrm{~L}$ de hipoclorito de sódio $(\mathrm{NaClO})$ a $12 \%, 3 \mathrm{~mL}$ de ácido clorídrico $(\mathrm{HCl})$ e $20 \mathrm{~g}$ de hidróxido de sódio comercial $(\mathrm{NaOH})$, dissolvidos em $1 \mathrm{~L}$ de água. Os porta-enxertos avaliados foram o 'Trifoliata' (Poncirus trifoliata [L.] Raf.), o citrangeiro 'C37' [Poncirus trifoliata (L.) Raf. x Citrus sinensis (L.) Osbeck.], o citrumeleiro 'Swingle' [P. trifoliata x (L.) Raf. x C. paradisi Macf.] e a tangerineira 'Sunki' (C. sunki hort. ex Tan.). Os porta-enxertos 'C37' e 'Trifoliata' beneficiaram-se da escarificação química do tegumento, apresentando maior velocidade e taxa de emergência das plântulas e maior taxa de emergência, aos 45 dias após a semeadura (DAS). Por outro lado, os porta-enxertos 'Swingle' e 'Sunki' apresentaram uma redução da emergência das plântulas, quando suas sementes foram submetidas à escarificação química do tegumento. As plantas de 'C37' e 'Trifoliata', oriundas de sementes escarificadas, apresentaram diâmetro ao nível do colo e acúmulo de massa seca significativamente superiores aos $150 \mathrm{DAS}$, em relação às plantas oriundas de sementes com o tegumento intacto.

Termos para indexação: Citrus spp., propagação, ambiente protegido, dormência de sementes, desenvolvimento vegetativo.

\section{CHEMICAL SCARIFICATION AND INITIAL DEVELOPMENT OF CITRIC ROOTSTOCKS}

\begin{abstract}
The aim of this study was to evaluate emergence and vegetative development of different citric rootstocks derived from chemically scarified seeds. A randomized block design was used in a $2 \times 4$ factorial (scarification $\mathrm{x}$ rootstocks) with three blocks. Each plot had 20 plastic tubes. The seed chemical treatment was a solution composed by $0.5 \mathrm{~L}$ of $12 \%$ sodium hypochlorite $(\mathrm{NaClO}), 3 \mathrm{~mL}$ of chloridric acid $(\mathrm{HCl})$ and $20 \mathrm{~g}$ of commercial sodium hydroxide $(\mathrm{NaOH})$, dissolved in $1 \mathrm{~L}$ of water. The evaluated rootstocks were 'Trifoliata'(Poncirus trifoliata [L.] Raf.), citrange 'C37' [Poncirus trifoliata (L.) Raf. x Citrus sinensis (L.) Osbeck.], citrumelo 'Swingle' [P. trifoliata (L.) Raf. x C. paradisi Macf.] and tangerine 'Sunki' (C. sunki hort. ex Tan.). Rootstocks 'Trifoliata' and 'C 37 ' had benefits with tegument chemical scarification, presenting faster seedling emergence, greater seedling emergence rate and greater emergence after 45 days. On the other hand, the rootstocks 'Swingle' and 'Sunki' presented a seedling emergence reduction when their seeds were submitted to chemical scarification in the tegument. Plants ' $\mathrm{C} 37$ ' and 'Trifoliata' from scarified seeds presented diameter and dry mass accumulation significantly higher 150 days after the sowing date, at soil level, as compared to plants derived from intact tegument seeds.
\end{abstract}

Index terms: Citrus spp., propagation, protected environment, seed dormancy, vegetative development.

\footnotetext{
1(Trabalho 210-08) Recebido em: 11-08-2009. Aceito para publicação em: 28-01-2009. Apoio Financeiro CAPES. Extraído da Tese apresentada pelo primeiro autor junto ao PpgFitotecnia / Faculdade de Agronomia / UFRGS.

${ }_{2}^{2}$ Doutor em Fitotecnia - área de concentração Horticultura - opção Fruticultura / Faculdade de Agronomia / UFRGS. - CEP: 91540 000 - Porto Alegre-RS. Email: plima37@yahoo.com.br

${ }^{3}$ Prof Dr. Depto de Horticultura e Silvicultura / Faculdade de Agronomia / UFRGS - CEP: 91540-000 - Porto Alegre-RS. Email: gilmarschafer@hotmail.com

${ }^{4}$ Prof Dr. Depto de Horticultura e Silvicultura / Faculdade de Agronomia / UFRGS - CEP: 91540-000 - Porto Alegre-RS. Bolsista do Conselho Nacional de Desenvolvimento Científico e Tecnológico Email: pvdsouza@ufrgs.br

${ }^{5}$ Bolsista de Iniciação Científica, Acadêmico do curso de Agronomia / UFRGS - CEP: 91540-000 - Porto Alegre-RS.

Email: abeltodeschini@yahoo.com.br
} 


\section{INTRODUÇÃO}

Na propagação de plantas cítricas, utilizam-se as sementes para a produção de porta-enxertos. Uma das características exploradas nos porta-enxertos cítricos é a apomixia, processo pelo qual há a formação de embriões sem que tenha ocorrido fecundação (Frost \& Soost, 1968). Neste caso, são produzidos o embrião zigótico e embriões oriundos de divisões mitóticas do nucelo, sem a intervenção de gametas, chamados embriões nucelares ou apomíticos. Estes embriões, oriundos a partir da multiplicação de um conjunto de células do saco embrionário ou da nucela, apresentam a mesma constituição genética do progenitor feminino, dando origem a uma planta idêntica à planta-mãe (Souza et al., 2002).

Algumas variedades de porta-enxertos de citros têm apresentado problemas de uniformidade de germinação, possivelmente sendo consequência de algum tipo de dormência, devido aos tegumentos que envolvem as sementes, atuando como uma barreira física à embebição de água e difusão de gases ou, ainda, pela presença, no tegumento, de algum inibidor de desenvolvimento do embrião (Oliveira et al., 2006; Oliveira \& Scivittaro, 2007).

As sementes dos gêneros Citrus e Poncirus são constituídas por dois tegumentos. O interno, chamado de tégmen, é delgado e composto, predominantemente, por substâncias do endosperma e do nucelo. O externo, chamado de testa, é formado pela epiderme da parede do óvulo, sendo mais espesso e lenhoso, havendo presença de lignina em quantidade variável segundo a espécie (Frost \& Soost, 1968).

Quando se considera o custo de produção de mudas cítricas em ambiente protegido, o tempo de formação da muda é muito importante, pois, diminuindo o tempo de permanência da muda no viveiro, aumenta o número de ciclos de produção de mudas durante a vida útil da estrutura física e aumenta a eficiência da utilização de mão de obra, reduzindo os gastos com defensivos agrícolas e fertilizantes por ciclo.

$\mathrm{O}$ alto custo das sementes e da estrutura do sistema de produção de mudas em ambiente protegido requer a obtenção de elevadas taxas de germinação e uniformidade de emergência das plântulas, sendo que a variabilidade na germinação acarreta posterior desuniformidade das plantas ao longo do processo de produção de mudas. Então, para a obtenção de porta-enxertos vigorosos, necessita-se utilizar sementes com qualidade genético-sanitária garantida e propiciar condições favoráveis à germinação e ao desenvolvimento das plântulas.

Neste sentido, faz-se necessário testar mé- todos de remoção do tegumento, que não causem nenhum tipo de dano ao embrião e que proporcionem uniformidade na germinação e na emergência de plântulas, bem como avaliar a influência do tegumento na germinação de sementes das diversas cultivares de porta-enxertos cítricos.

Diversos tratamentos são utilizados no tegumento de sementes com a finalidade de aumentar a taxa de germinação e a uniformidade de emergência das plantas. Processos físicos, como a imersão em água a diferentes temperaturas, calor seco, calor úmido, frio seco ou radiação, são exemplos. Também, há processos químicos com soluções ácidas, enzimas ou solventes orgânicos, e substâncias estimuladoras de germinação, como nitrato de potássio ou reguladores de crescimento. Além destas técnicas, há a remoção manual do tegumento (Oliveira et al., 2006).

O objetivo deste trabalho foi avaliar a emergência e o desenvolvimento vegetativo inicial de diferentes porta-enxertos cítricos provenientes de sementes escarificadas quimicamente.

\section{MATERIAL E MÉTODOS}

O experimento foi conduzido em casa de vegetação da Estação Experimental Agronômica da Universidade Federal do Rio Grande do Sul (EEA/ UFRGS), situada na Rodovia BR 290 (km 146), em Eldorado do Sul-RS

$\mathrm{O}$ delineamento experimental adotado foi o de blocos casualizados, em esquema fatorial, com três blocos, totalizando oito tratamentos, e cada unidade experimental, constituída por 20 tubetes.

Comparou-se a realização ou não de escarificação química das sementes em quatro porta-enxertos cítricos antes de sua semeadura, sendo eles: o Trifoliata [Poncirus trifoliata (L.) Raf.]; o citrangeiro 'C37' [Poncirus trifoliata (L.) Raf. x Citrus sinensis (L.) Osbeck.]; o citrumeleiro 'Swingle' [P. trifoliata x (L.) Raf. x C. paradisi Macf.]; e a tangerineira 'Sunki' (C. sunki hort. ex. Tan.).

Foram utilizadas sementes oriundas das plantas cultivadas na coleção de citros da EEA/UFRGS. A metodologia adotada para a extração das sementes é descrita por Souza \& Schäfer (2006). Essas sementes permaneceram em geladeira $\left(4\right.$ a $\left.6{ }^{\circ} \mathrm{C}\right)$ por um período aproximado de cinco meses, dentro de sacos plásticos, com fungicida Captan, até o momento da semeadura. No momento da semeadura, foi retirada uma amostra de 30 sementes de cada cultivar de porta-enxerto utilizada no experimento para mensurar o comprimento e o diâmetro das sementes.

O tratamento químico realizado nas sementes foi observado no trabalho de Oliveira et al. (2006) 
e constituiu-se da imersão de $50 \mathrm{~g}$ de sementes, sob agitação por 45 minutos, em solução contendo 0,5 L de hipoclorito de sódio ( $\mathrm{NaClO}$ ) a $12 \%, 3 \mathrm{~mL}$ de ácido clorídrico $(\mathrm{HCl})$ e $20 \mathrm{~g}$ de hidróxido de sódio comercial $(\mathrm{NaOH})$, dissolvidos em $1 \mathrm{~L}$ de água, com posterior lavagem em água corrente e remoção do tegumento, esfregando-se as sementes umas sobre as outras, no interior de um pano úmido.

A semeadura foi realizada em meados de agosto de 2007, em tubetes cônicos de polietileno preto (volume de $120 \mathrm{~cm}^{3}$ ), vazados na parte basal, fixados em bancadas metálicas a um metro da superfície. Foram colocadas três sementes por tubete, à profundidade de $1 \mathrm{a} 2 \mathrm{~cm}$, conforme o tamanho destas. Aos 60 dias após a semeadura, foi realizado um desbaste nas plântulas, deixando-se apenas uma plântula por tubete. Foi utilizado o substrato Plantmax Hortaliças HT (fabricante Eucatex ${ }^{\circledR}$ - segundo informações do fabricante é composto de cascas processadas e enriquecidas, vermiculita expandida e turfa processada e enriquecida).

As irrigações foram feitas mediante um sistema de subirrigação por capilaridade (Schäfer, 2004). Este constituiu-se da imersão de 60 a $70 \%$ do comprimento dos tubetes dispostos em suportes sob bandeja metálica, a partir da base, em solução em água, por um período de uma hora, duas vezes ao dia. O sistema era acionado por um timer eletrônico, às 9 horas e às 17 horas. Uma solução nutritiva foi adicionada à água de irrigação a partir dos 60 dias após a semeadura (DAS). A solução nutritiva foi totalmente trocada a cada 15 dias. Esta solução tinha uma concentração de 2,0 g $\mathrm{L}^{-1}$ e uma relação entre os nutrientes de: $\mathrm{N}-1 ; \mathrm{P}-0,14$; $\mathrm{K}-0,34$; Ca-1,41 e Mg-0,13.

Foram avaliadas a taxa e a velocidade de emergência das sementes, determinadas mediante o percentual de tubetes nos quais emergiu ao menos uma plântula (PTEUP).

O desenvolvimento vegetativo foi avaliado através de medições do diâmetro ao nível do colo, em $\mathrm{mm}$; comprimento da parte aérea, medida do colo até o ápice da planta, em cm; área foliar por planta (AFP), $\mathrm{em} \mathrm{cm}^{2}$; e área foliar por folha (AFF), em $\mathrm{cm}^{2}$, medida através da passagem das folhas por um medidor de área foliar de marca LI-Cor, modelo LI - 3100; e o número de folhas por planta (NFP). O acúmulo de massa seca das raízes (MSR), da parte aérea e total (raiz + parte aérea) (MSPA) por planta, em gramas, foi obtido pela secagem à estufa, com temperatura de 65 ${ }^{\circ} \mathrm{C}$, até peso constante. Não foi avaliado o desenvolvimento vegetativo dos porta-enxertos citrumeleiro 'Swingle' e tangerineira 'Sunki', devido à baixa taxa de germinação de suas sementes, quando submetidas a escarificação química para a retirada do tegumento, não permitindo a comparação entre as plantas oriundas ou não de sementes escarificadas.

As médias foram submetidas à análise de variância e comparadas pelo teste de Duncan, ao nível de $5 \%$ de significância, enquanto a variável comprimento da parte aérea dos porta-enxertos, ao longo do tempo, foi submetida à análise de regressão. Os dados referentes à emergência dos porta-enxertos foram transformados para arc sen raiz quadrada de $\mathrm{x} / 100$.

\section{RESULTADOS E DISCUSSÃO}

Houve interação significativa entre a escarificação química das sementes e os diferentes portaenxertos, para a variável percentagem de emergência de plântulas (Tabela 1). A escarificação química acelerou a germinação das sementes do citrangeiro FEPAGRO 'C37' e do 'Trifoliata'. Ao contrário, a tangerineira 'Sunki' e o 'Citrumeleiro Swingle' foram prejudicados pela escarificação química, germinando em menor quantidade e velocidade.

Em ausência de escarificação, os portaenxertos FEPAGRO 'C37' e 'Trifoliata' apresentaram taxa de germinação pequena nos primeiros 30 DAS, atingindo os valores máximos aos 45 DAS (Tabela 1). Com a escarificação das sementes, houve uma aceleração significativa na germinação destes porta-enxertos, atingindo um valores próximos da germinação máxima aos $30 \mathrm{DAS}$, com pequeno acréscimo na germinação após esta data.

Por outro lado, a escarificação química foi prejudicial à germinação da tangerineira 'Sunki' e do citrumeleiro 'Swingle', ocorrendo uma redução drástica da emergência das plântulas, com a remoção do tegumento. Com o tegumento intacto, as sementes destes porta-enxertos atingiram valores superiores de germinação final (Tabela 1).

A baixa taxa de emergência dos porta-enxertos 'Swingle' e 'Sunki', submetidos a escarificação química, inviabilizou a avaliação do desenvolvimento vegetativo destes em comparação às plantas destes mesmos porta-enxertos, onde as sementes não foram submetidas a escarificação química.

O comprimento médio das sementes de tangerineira 'Sunki' foi de 7,33 mm, e o diâmetro médio, de 5,25 mm. As sementes de 'Trifoliata' tiveram um comprimento médio de $10,65 \mathrm{~mm}$ e diâmetro médio de $7,18 \mathrm{~mm}$, valores semelhantes aos apresentados pelo citrangeiro ' $\mathrm{C} 37$ ' e pelo citrumeleiro 'Swingle', com 12,55 e 12,00 mm de comprimento médio 6,76e $7,05 \mathrm{~mm}$, respectivamente. Por este tamanho e, principalmente, tegumento mais delgado das sementes de tangerineira 'Sunki', este pode ter sofrido dano pela 
escarificação química, prejudicando sua germinação. Porém, esta explicação não se aplica ao citrumeleiro 'Swingle', que também foi prejudicado pela escarificação, mas apresenta sementes de dimensões semelhantes ao 'C37' e 'Trifoliata'.

A época do ano em que a semeadura é realizada, é um fator relevante na germinação de porta-enxertos de citros. Embora a germinação ocorra na faixa de temperatura de $12^{\circ} \mathrm{C}$ a $40^{\circ} \mathrm{C}$, o desenvolvimento dos porta-enxertos é otimizado em temperaturas de 26 a $28^{\circ} \mathrm{C}$ (Oliveira \& Scivittaro, 2007).

A implantação do presente estudo ocorreu em meados de agosto de 2007, tendo ocorrido temperaturas médias inferiores a $12^{\circ} \mathrm{C}$, nos primeiros 20 dias (Departamento de Agrometereologia/Faculdade de Agronomia/UFRGS, 2008), o que deve ter colaborado para esta desuniformidade na velocidade de germinação.

Os resultados obtidos em relação à germinação dos porta-enxertos corroboraram um trabalho realizado com diferentes porta-enxertos em ambiente protegido, onde os citrangeiros FEPAGRO ' $\mathrm{C} 13$ ' e 'C37' alcançaram maior velocidade de germinação que o 'Trifoliata', que atingiu um nível pouco superior a $70 \%$ de germinação (Schäfer, 2004). Para este autor, a temperatura e a cultivar foram os fatores que mais influenciaram na velocidade de germinação dos porta-enxertos cítricos, principalmente quando fatores como umidade são adequados. De acordo com o mesmo autor, as plantas começaram a emergir aproximadamente aos 21 dias após a semeadura (DAS), com um pico aos 48 dias. Verificou que, em geral, aos 48 DAS, aproximadamente $80 \%$ das sementes haviam emergido. Em média, os incrementos após essa data não superaram os 4\%.

Em um trabalho realizado por Oliveira et al. (2006), no interior de viveiro telado, usando sementes escarificadas e não escarificadas, semeadas em um período com temperatura média mínima de 20,5 ${ }^{\circ} \mathrm{C}$ e máxima de $30,4{ }^{\circ} \mathrm{C}$, bem mais elevadas do que as do presente experimento, a emergência das plantas de 'Trifoliata' foi mais rápida, concentrando-se do 6- ao $30^{\circ}$ - dia após a semeadura, e a percentagem final variou de 88,7 a 99,7 \%, evidenciando a influência da temperatura na germinação de sementes.

Oliveira et al. (2006) também trabalharam com tratamentos químicos para remoção do tegumento e concluíram que a escarificação com hipoclorito de sódio aumenta a velocidade de emergência do 'Trifoliata', o que vem a conciliar com o comportamento apresentado pelos porta-enxertos 'Trifoliata' e FEPAGRO 'C 37' neste estudo.

Em outro trabalho avaliando o efeito do tegu- mento na emergência de plântulas de 'Trifoliata', esta foi significativamente maior e mais rápida nas sementes em que o tegumento foi removido. A realização de um orifício com estilete na região do endosperma das sementes também favoreceu o processo germinativo. Os autores confirmam a ação do tegumento como um inibidor físico do processo de germinação de sementes de 'Trifoliata', mas com o mecanismo ainda não elucidado (Oliveira \& Scivittaro, 2007).

A resposta positiva apresentada na germinação e emergência do porta-enxerto 'Trifoliata' em relação aos tratamentos de sementes pode ser explicada pelo fato de suas sementes apresentarem um comportamento recalcitrante, perdendo rapidamente a viabilidade durante o armazenamento, além de seu tegumento ser coriáceo, o que dificulta a embebição de água ou a difusão de gases, além de favorecer o aparecimento da podridão da semente durante a germinação, principalmente em temperaturas inferiores a $12{ }^{\circ} \mathrm{C}$ (Oliveira et al., 2006).

A obtenção de porta-enxertos vigorosos depende da qualidade das sementes utilizadas, que sofrem interferência do período e das condições de armazenamento, principalmente da temperatura do ambiente e do teor de água na semente (Martins et al., 2007). As sementes de 'Trifoliata' e seus híbridos são mais sensíveis ao armazenamento do que as sementes dos demais porta-enxertos utilizados na produção de mudas de citros (Koller et al., 1993). De acordo com Oliveira et al. (2003), as sementes de 'Trifoliata' apresentam perda da viabilidade após 30 dias de armazenamento em condições de temperatura e umidade não controladas e relatam que o armazenamento em câmara fria (temperatura de $4^{\circ} \mathrm{C}$ e umidade relativa do ar de $70 \%$ ) é o método mais eficiente na conservação das sementes de 'Trifoliata', independentemente do tempo de armazenamento.

Como o 'Trifoliata' é um porta-enxerto de caráter caducifólio, mecanismo de defesa das plantas a condições adversas de ambiente, provavelmente suas sementes também têm alguma característica genética associada à defesa, manifestado por sua dormência Como o FEPAGRO 'C37' é oriundo do cruzamento entre Poncirus trifoliata e Citrus sinensis, pode ter herdado a característica do $P$. trifoliata. Por outro lado, o citrumeleiro 'Swingle' também é filho do $P$. trifoliata, mas em cruzamento com Citrus paradisi. Neste caso, as sementes provavelmente herdaram características do último, pois foram prejudicadas pela escarificação.

$\mathrm{Na}$ Tabela 2, constam as características de desenvolvimento vegetativo dos porta-enxertos citrangeiro FEPAGRO 'C37' e 'Trifoliata', passados 150 dias da semeadura, oriundos de sementes previa- 
mente submetidas ou não a um tratamento químico. Quanto à altura das plântulas, não houve diferença significativa entre os porta-enxertos. O FEPAGRO 'C37' mostrou-se superior ao 'Trifoliata', quanto ao diâmetro ao nível do colo, área foliar por folha e por planta, e acúmulo de massa seca da raiz $\left(\mathrm{g} \mathrm{planta}^{-1}\right)$. $\mathrm{O}$ 'Trifoliata', por sua vez, apresentou maior número de folhas. A massa seca da parte aérea não se mostrou significativamente diferente entre os porta-enxertos (Tabela 2).

A diferença entre os porta-enxertos é comum de ser encontrada, podendo-se atribuí-la às diferentes características genéticas, que influenciam na capacidade de uso de luz e $\mathrm{CO}_{2}$, afetando a absorção, o transporte e a interação dos nutrientes dentro da planta (Fochesato et al., 2006). Schäfer (2004), aos 120 DAS, obteve parâmetros de desenvolvimento vegetativo diferenciados para os porta-enxertos ' $T r i-$ foliata' e citrangeiro FEPAGRO 'C37'. O 'Trifoliata' apresentou baixo índice de área foliar, devido às características intrínsecas da própria espécie, pois é normal este porta-enxerto apresentar folhas menores quando comparado a outros porta-enxertos cítricos (Schäfer, 2004).

As plantas oriundas de sementes tratadas quimicamente apresentaram-se significativamente superiores em relação às plantas oriundas de sementes com o tegumento intacto, em relação ao diâmetro ao nível do colo e acúmulo de massa seca na raiz e total $\left(\right.$ g planta $\left.^{-1}\right)$ (Tabela 2). O diâmetro é um fator importante no desenvolvimento dos porta-enxertos, pois é uma das características que definem o momento da enxertia (Oliveira et al., 2001). As variáveis área foliar por folha e por planta, número de folhas por planta e massa seca da parte aérea ( $\mathrm{g}$ planta $\left.\mathrm{f}^{-1}\right)$ não diferiram significativamente pela escarificação (Tabela 2).

Resultado semelhante foi observado para as sementes de 'Trifoliata' submetidas à escarificação química que resultaram, aos 65 dias após a semeadura
(DAS), em plantas com diâmetro do caule, produção de matéria seca das raízes e total significativamente maiores que as plantas oriundas de sementes com o tegumento intacto ou de sementes onde foi realizada a retirada manual do tegumento (Oliveira et al., 2006).

Este tratamento químico pode acelerar o processo de embebição e, portanto, acelerar o início da germinação. Como consequência, podem-se obter plantas com maior diâmetro e maior acúmulo de reservas em menor período de tempo (Oliveira et al., 2006). Além disso, o hipoclorito de sódio ( $\mathrm{NaClO})$, o ácido clorídrico $(\mathrm{HCl})$ e o hidróxido de sódio $(\mathrm{NaOH})$ podem auxiliar protegendo as sementes contra as podridões.

A altura da parte aérea apresentou crescimento linear ao longo do tempo de cultivo, não apresentando interação entre porta-enxertos e a realização de escarificação química das sementes (Figura 3). Nota-se que os porta-enxertos atingiram os $10 \mathrm{~cm}$ de altura por volta dos 100 dias após a semeadura (DAS), altura que já permite a repicagem para recipientes maiores (Oliveira et al., 2001).

O método de escarificação química é de fácil e rápida execução, além de apresentar baixo custo, quando comparado à remoção manual do tegumento, podendo ser utilizado em grande escala para o porta-enxerto 'Trifoliata' e para as demais espécies de porta-enxertos que venham a apresentar problemas de germinação. No entanto, faz-se necessário testar diferentes concentrações dos componentes da solução utilizada, bem como o tempo de imersão das sementes na solução, com a finalidade de estudar a possível interação entre estes fatores e as diferentes espécies de porta-enxertos.

TABELA 1 - Porcentagem de tubetes com ao menos uma plântula emergida de porta-enxertos cítricos submetidos (CEQ) ou não (SEQ) à escarificação química das sementes antes da semeadura, aos 15; 30 e 45 dias após a semeadura (DAS), EEA/UFRGS, Eldorado do Sul-RS, 2007.

\begin{tabular}{|c|c|c|c|c|c|c|}
\hline \multirow[b]{3}{*}{ Porta-enxertos } & \multicolumn{6}{|c|}{ etes com ao menos uma plântula emergid } \\
\hline & \multicolumn{2}{|c|}{$15 \mathrm{DAS}$} & \multicolumn{2}{|c|}{$30 \mathrm{DAS}$} & \multicolumn{2}{|c|}{$45 \mathrm{DAS}$} \\
\hline & CEQ & SEQ & CEQ & SEQ & CEQ & SEQ \\
\hline 'C 37' & $66,82 \mathrm{aA}^{1}$ & $6,70 \mathrm{bB}$ & $91,98 \mathrm{aA}$ & $23,83 \mathrm{bB}$ & $97,76 \mathrm{aA}$ & $86,99 \mathrm{aA}$ \\
\hline 'Trifoliata' & $38,32 \mathrm{aB}$ & $0,00 \mathrm{bC}$ & $56,69 \mathrm{aB}$ & $0,00 \mathrm{bC}$ & $60,14 \mathrm{aB}$ & $43,27 b C$ \\
\hline 'Sunki' & $1,14 \mathrm{bC}$ & $24,89 \mathrm{aA}$ & $11,14 b C$ & $56,73 \mathrm{aA}$ & $11,14 b C$ & $73,56 \mathrm{aB}$ \\
\hline 'Citrumelo' & $2,24 \mathrm{aC}$ & $3,29 \mathrm{aBC}$ & $11,57 \mathrm{bC}$ & $20,91 \mathrm{aB}$ & $15,00 \mathrm{bC}$ & $51,67 \mathrm{aC}$ \\
\hline C.V. $(\%)$ & & & & & & \\
\hline
\end{tabular}

${ }^{1}$ Médias seguidas por letras diferentes e minúsculas na linha e maiúsculas na coluna, dentro de cada época de avaliação, diferem significativamente pelo teste de Duncan, ao nível de $5 \%$ de probabilidade. 
TABELA 2 - A (Altura da parte aérea), D (Diâmetro ao nível do colo AFF (Área Foliar por Folha), AFP (Área Foliar por Planta), NFP (Número de Folhas por Planta), MSR (Massa Seca de Raiz), MSPA (Massa Seca da Parte Aérea) e MST (Massa Seca Total),dos porta-enxertos Poncirus trifoliata e citrangeiro 'C37' submetidos (CEQ) ou não (SEQ) à escarificação química das sementes antes da semeadura, e cultivados em substrato e em ambiente protegido, 150 dias após a semeadura. EEA/UFRGS, Eldorado do Sul-RS, 2007.

\begin{tabular}{|c|c|c|c|c|c|c|c|c|}
\hline Porta-enxerto & $\begin{array}{c}\mathrm{A} \\
(\mathrm{cm}) \\
\end{array}$ & $\begin{array}{c}\mathrm{D} \\
(\mathrm{mm})\end{array}$ & $\begin{array}{l}\mathrm{AFF} \\
\left(\mathrm{cm}^{2}\right)\end{array}$ & $\begin{array}{c}\text { AFP } \\
\left(\mathrm{cm}^{2}\right)\end{array}$ & NFP & $\begin{array}{c}\text { MSR } \\
(\mathrm{g}) \\
\end{array}$ & $\begin{array}{c}\text { MSPA } \\
(\mathrm{g})\end{array}$ & $\begin{array}{c}\text { MST } \\
(\mathrm{g}) \\
\end{array}$ \\
\hline 'C37' & 24,80 & $2,15 \mathrm{a}^{1}$ & $4,68 \mathrm{a}$ & $46,84 a$ & $10,00 \mathrm{~b}$ & $0,22 \mathrm{a}$ & 0,81 & 1,03 \\
\hline 'Trifoliata' & 27,16 & $2,10 \mathrm{~b}$ & $2,61 \mathrm{~b}$ & $34,14 b$ & $13,00 \mathrm{a}$ & $0,16 b$ & 0,71 & 0,85 \\
\hline \multicolumn{9}{|c|}{ Tratamento de sementes } \\
\hline CEQ & 26,49 & $2,29 a$ & 3,67 & 42,39 & 11,94 & $0,22 \mathrm{a}$ & 0,69 & $1,06 \mathrm{a}$ \\
\hline SEQ & 25,47 & $1,95 b$ & 3,62 & 38,55 & 11,12 & $0,16 \mathrm{~b}$ & 0,84 & $0,82 b$ \\
\hline C.V. $(\%)$ & 7,7 & 6,5 & 1,8 & 14,3 & 13,5 & 10,4 & 19,0 & 17,8 \\
\hline
\end{tabular}

${ }^{1}$ Medias seguidas por letras diferentes e minúsculas na coluna diferem significativamente, pelo teste de Duncan, ao nível de $5 \%$ de probabilidade.



DAS

FIGURA 1 - Comprimento da parte aérea, dias após a semeadura (DAS), ao longo do tempo, de portaenxertos cítricos submetidos, ou não, a um tratamento químico para a remoção do tegumento, cultivados em substrato e em ambiente protegido. EEA/UFRGS, Eldorado do Sul-RS, 2008.

\section{CONCLUSÕES}

1-A escarificação química aumenta a germinação e o desenvolvimento inicial dos porta-enxertos FEPAGRO 'C37' e 'Trifoliata' e prejudica a germinação da tangerineira 'Sunki' e do Citrumeleiro 'Swingle'.

2-O porta-enxerto FEPAGRO 'C37', na fase de sementeira, apresenta vigor vegetativo superior ao 'Trifoliata', quando produzido em ambiente protegido, sendo indicado para acelerar o desenvolvimento da muda e como alternativa à diversificação de porta-enxertos nas condições climáticas do Rio Grande do Sul.

\section{AGRADECIMENTOS}

À Coordenação de Aperfeiçoamento de Pessoal de Nível Superior - CAPES, pela concessão da bolsa de estudo, que possibilita a realização do Curso de Doutorado e a execução da Pesquisa, por parte do primeiro autor.

\section{REFERÊNCIAS}

FOCHESATO, M.L.; SOUZA, P.V.D.; SCHÄFER, G.; MACIEL, H.S. Produção de mudas cítricas em diferentes porta-enxertos e substratos comerciais. Ciência Rural, Santa Maria, v.36, n.5, p.1397-1403, 2006. 
FROST, H.B.; SOOST, R.K. Seed reproduction; development of gametes and embryos. In: REUTHER, W.; BATCHELOR, L.D.; WEBBER, H.J. (Ed.). The citrus industry. Berkeley: University of California Press, 1968. v.2, p.290-324.

KOLLER, O.L.; STUKER, H.; VERONA, L.A.F.; SOPRANO, E. Efeito da umidade da semente, da temperatura de estocagem e da duração de estocagem sobre a germinação de Poncirus trifoliata e de outros porta-enxertos de citros. Revista Brasileira de Fruticultura, Jaboticabal,v. 15, n. 1, p. 27-33, 1993.

MARTINS, L.; SILVA, W.R da; LAGO, A.A.do. Conservação de sementes de Tangerina 'Cleópatra': Teor de água e temperatura do ambiente. Revista Brasileira de Sementes, Jaboticabal, v. 29, n. 1, p. 178-185, 2007.

OLIVEIRA, R.P.; SCIVITTARO, W.B.; BORGES, R.S.; NAKASU, B.H. Mudas de citros. Pelotas: Embrapa de Clima Temperado, 2001.32p. (Sistemas de produção, 1). Disponível em: <http://www.cpact. embrapa.br/publicacoes/catalogo/tipo/sistemas/mudas/cap02.htm>. Acesso em: 03 jul. 2005.

OLIVEIRA, R.P. de; SCIVITTARO, W.B. Formação do porta-enxerto Trifoliata: época de semeadura e tegumento na emergência de plântulas. Ciência Rural, Santa Maria v.37, n. 1, p. 281-283, 2007.
OLIVEIRA, R. P. DE; SCIVITTARO,W.B.; RADMANN, E.B. Escarificação química da semente para favorecer a emergência e o crescimento do porta-enxerto Trifoliata. Pesquisa Agropecuária Brasileira, Brasília, v.41, n. 9, p. 1429-1433, 2006.

OLIVEIRA, R. P. DE; SCIVITTARO,W.B.; RADMANN, E.B. Procedimentos para o armazenamento de sementes de Poncirus trifoliata (L.) Raf. Revista Brasileira de Fruticultura, Jaboticabal, v. 25, n. 3, p. 461-463, 2003b.

SCHÄFER, G. Produção de porta-enxertos cítricos em recipientes e ambiente protegido no Rio Grande do Sul. 2004. 129 f. Tese (Doutorado em Fitotecnia) - Faculdade de Agronomia, Universidade Federal do Rio Grande do Sul, Porto Alegre, 2004.

SOUZA, P.V. de S.; SCHÄFER, G. Produção de mudas de laranjeiras. In: KOLLER, O.C. (Org.). Citricultura: 1. Laranja: tecnologia de produção, pós-colheita, industrialização e comercialização. Porto Alegre: Ed. Cinco Continentes, 2006. cap. 5, p. 55-87.

SOUZA, H.U. de et al. Efeito do ácido giberélico sobre a germinação de sementes e porta-enxertos cítricos. Revista Brasileira de Fruticultura, Jaboticabal, v. 24, n. 2, p. 496-499, 2002. 